China Perspectives

54 | July- August 2004

Varia

\title{
Energy and Globalisation: Oil and Gas in China
}

\section{Alain Sepulchre}

\section{OpenEdition}

Journals

Édition électronique

URL : http://journals.openedition.org/chinaperspectives/2962

DOI : 10.4000/chinaperspectives.2962

ISSN : 1996-4617

\section{Éditeur}

Centre d'étude français sur la Chine contemporaine

\section{Édition imprimée}

Date de publication : 1 juillet 2004

ISSN : 2070-3449

\section{Référence électronique}

Alain Sepulchre, «Energy and Globalisation: Oil and Gas in China », China Perspectives [En ligne], 54 I July- August 2004, mis en ligne le 17 avril 2008, consulté le 14 novembre 2019. URL : http:// journals.openedition.org/chinaperspectives/2962 ; DOI : 10.4000/chinaperspectives.2962

Ce document a été généré automatiquement le 14 novembre 2019.

(c) All rights reserved 


\title{
Energy and Globalisation: Oil and Gas in China
}

\author{
Alain Sepulchre
}

1 All the evidence, from news desk analysis about oil and gas in China to the incredible growth that China has experienced in the ten years from 1990 to 2000, points to a Chinese energy scene that is already "global". Selective macro data and investigative reports show China to be a new global partner in this industry. Yet, critical factors show a country not truly engaged in a definite globalisation process.

With a daily production of 3.3 million barrels of oil (bpd) and a consumption of 5.45 million bpd, in 2003 China was the sixth biggest producer and the second biggest oil consumer in the world. Its fast-growing and unequalled demand for massive imports makes China an important actor. Yet its position in the global oil market, dominated by major oil-supply countries and global companies, does not appear so important.

With the emergence of its three big oil \& gas companies-CNPC (China National Petroleum Corporation), Sinopec Group (China Petroleum and Chemical Company) and CNOOC (China National Offshore Company) ${ }^{1}$-a comprehensive process of local industry reshuffling and restructuring has been taking place to establish an industry that reflects the values of a market economy system. Its potential to tap foreign investment and build the biggest ever oil derivatives market along global standards is perceived to be limitless. Yet its domestic market fundamentals appear as yet in early to midtransition from a base of heavy state interventionism and protectionism and only marginally integrating the emerging presence of the oil giants: ExxonMobil, Shell, British Petroleum (BP), Total and ChevronTexaco ${ }^{2}$.

In 2000 to 2001 the three Chinese companies successfully entered the international financial and business market with their IPO (Initial Public Offer ${ }^{3}$ )-Petrochina, Sinopec Corporation and $\mathrm{CNOOC}$ Limited. China owns now a trio of globalisable champions: a highly unique situation. Yet a fair comparative assessment of their performances versus those of the majors offers a long list of medium-performing characteristics and profiles, not fully in line with international standards and benchmarks.

Definition and scope of globalisation: three perspectives 
Globalisation has been variously defined, reflecting in part different disciplinary assumptions. An interdisciplinary group has recently offered a comprehensive definition of globalisation as "comprising a host of facts and observations such as the accelerated growth of world trade and investment since the mid-80s, the global distribution of the value-added chain of companies or the global integration of money and capital markets. Yet globalisation is not only an economic phenomenon, but rather includes...the emergence of other social values and ways of life"4.

6 We additionally call upon the integrative theoretical work of John Child. His conceptual analysis of a trans-national organisational framework implicated by a globalisation context ${ }^{5}$ assess the critical attributes of globalisation through a three-systems approach-material, institutional and ideational. Similarly he characterises the vector of changes within globalisation along this triple identities perspective.

7 Accordingly, we propose to investigate globalisation along a triple perspective. Firstly, a macroeconomic perspective will capture the situation and positioning of China in the energy world scene.

8 Secondly, a China or "domestic" perspective will relate its specific local oil and gas framework and playing field vis-à-vis the so-called material identities ${ }^{6}$. Our aim is to measure the place and role of economic and market fundamentals-such as market structure and efficiency, price fixing mechanisms, technology standards, competition standpoint-as well as to integrate the impact of major exogenous sources of material changes emerging from the majors and from other international investments in addition to emerging WTO regulations.

9 Thirdly, a comparative performances analysis between the three domestic champions and the majors (and some regional competitors) will be set up. A valuation process will be elaborated to position them vis-à-vis some global business institutional rules such as corporate governance and a normative matrix organisational system. Similarly, their standpoint vis-à-vis some global business values phenomena such as quality and consumer-driven corporate policy and a social environment promoting meritocracy and responsibility will be reviewed.

A macro-perspective: scenarios for four globalisation processes

10 China stands today as the second largest energy consumer-after the USA-and the third largest energy producer-behind the USA and Russia. China is also number one producer of coal and number two in installed power generation. Its massive growth requirement projections estimated by various sources put it as being potentially the largest market for energy products, services and technology and confirmed to be the biggest incremental source of energy demand for the 2000 to 2020 period taking about $23 \%$ of the world total ${ }^{7}$. Its primary energy demand jumped from 864 million tons of oil (Mtoe) in 1995 to 2.1 billion tons in 2020, which will significantly increase its global power, representing $11 \%$ of the global market in 1995 and up to $16 \%$ in 2020 . These figures legitimise China's uncontested presence within the worldwide energy framework.

Coal, the uncontested leader in a "low context" globalisation process

11 Table 1 , a detailed investigation through the spectrum of primary sources of energy ${ }^{8}$ shows a contrasting picture among the four different types; and accordingly, four specific and distinct areas of globalisation. 
Through its recent history China has uniquely been dependant on its domestic coal to supply most of its energy demand. This makes it the most dependant of any nation, currently 70\% dependence (down from 95\% in the 1950s), as well as the largest producer and consumer of coal worldwide. Future projections indicate a sustained dominance although slightly down, to about $66 \%$ in 2020 . Coal production (26\% in worldwide figures in 2001) ${ }^{9}$, and reserves being plentiful (third largest worldwide), self-sufficiency has been and will be granted for decades, theoretically putting China in a very reassuring and comfortable position of not needing to go global. Presumably as well, it guarantees comprehensive autonomy and independence in both business management and political leadership, therefore implying massive and long-term protectionism and some state-owned type of governance.

China energy needs (primary and secondary sources)

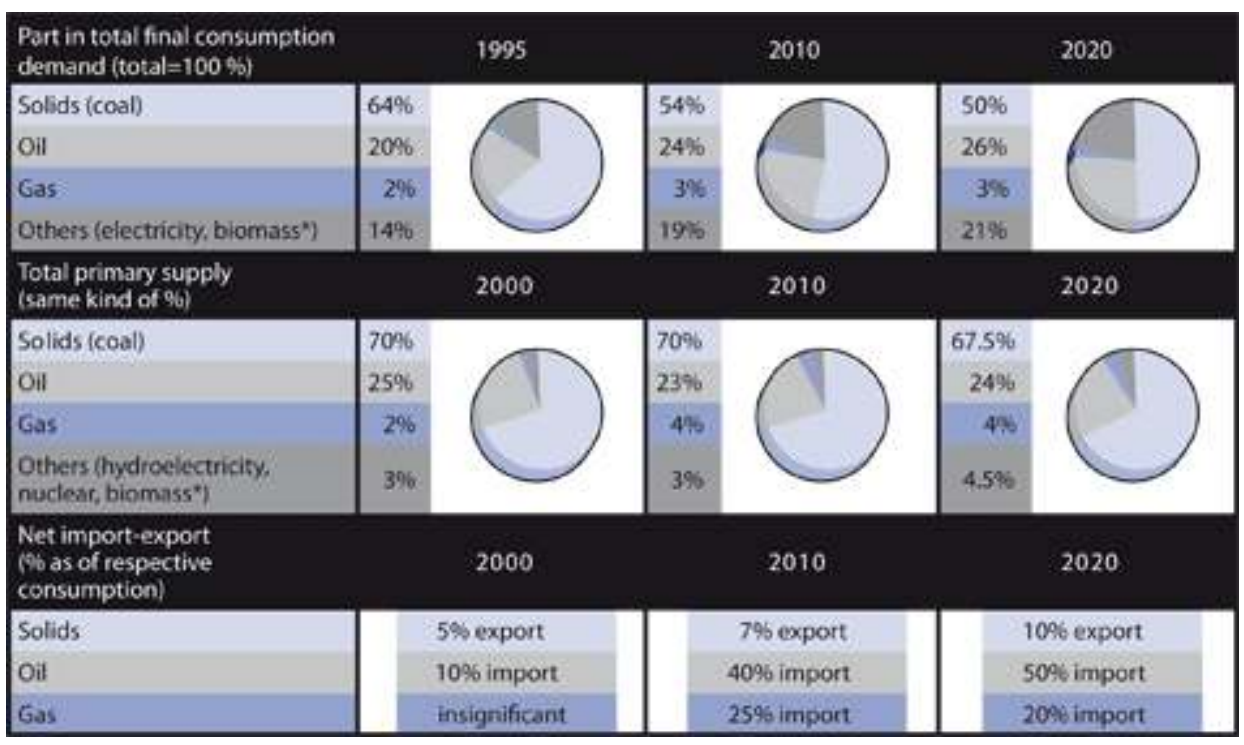

NB: * Commercial value only.

Sources: International Energy Agency (IEA), Developing China's Gas Market, Energy Policy Challenges, OECD, 2002. HEC Eurasia, La Grande Muraille de charbon, l'énergie en Chine au XXle siècle, HEC Eurasia Institute, Paris, 1999. IEA, China Worldwide Quest for Energy Security, IEA Press, 1999. Standard \& Poor's, World Energy Service Asia Pacific Outlook, Hong Kong, 1999. State Development Planning Commission (SDPC) data and personal documents. All pourcentages are a mix of those sources.

But China's coal industry appears no more completely disconnected from the global energy system with regard to other domestic primary sources of energy. Three of its fundamental characteristics handicap and counteract its contemplated isolation capability on paper. A first issue lies in the poor values of the domestic feedstock, both intrinsic and in terms of apparatus, and both reflecting a comparative heavy polluting effect and high average extraction and production costs due to the inefficiencies of the local mines. A second issue lies in localisation and material balance defects as the industry is concentrated in the north and west while demand is concentrated in the south and east. The third and final issue lies in the unstable obligation falling upon some export transactions to alleviate production imbalance risk, but without creating overwhelming repercussions for international prices-China being the second largest exporter in 2002.

14 These issues have three negative consequences. The most important is a gradual relative loss of its competitiveness and attractiveness (once all costs are taken into 
account following accepted accountable Western techniques), versus the more "modern" and much less polluting sources of energy that carry with them fewer logistic constraints in terms of transportation, and which are now in greater and more available supply. Another damaging loss of appeal questions its traditional supporting feedstock role supplying the bulk (about three-quarters) of electricity production. Its ability or inability to face booming electricity demands in coastal areas that are outstripping a bottlenecked transportation and supply chain, creating shortages as experienced during some peak times during $2003{ }^{10}$ are re-emerging as a contingent matter of concern now ${ }^{11}$, presents another consideration. Finally, its declining position as a reliable leading supplier to overseas markets is taking its toll through the accumulated effect of the previous two impacts, de facto institutionalising a situation prioritising domestic concerns ${ }^{12}$ against global market supply and demand patterns.

Important measures to correct this three-point situation have been taken since the mid- to late 1990s. Among them, the most "global" refer to closure of the most uncompetitive sites (mainly a vast number of small operations) and to the planned industry consolidation under the authority of the China Coal Industry Association-including a master project to set up eight to ten giant enterprises ${ }^{13}$. A key number of actions such as fundamental technology upgrades and technology transfers (i.e. coal gasification and coal-bed methane processes) as well as innovative supply chain improvements (such as coal-fired power plants) are also under implementation in association with massive infrastructure work (ongoing renovation and modernisation of rail, marine and road networks). Additionally, programmes are being set up for elementary environmental protection and social safety-both aiming at drastic reductions in emissions.

Overall, such "low-context globalisation" macro processes are made up of challenging steps and initiatives, within a domestic context dominantly "local", to transform as much as to elevate coal industry assets and its value chain to bring it in line with global partners/competitors and standards.

Oil-a medium-context process

Oil accounts for about $25 \%$ of China's energy, and shows a highly contrasting picture to gas in terms of globalisation.

On the one hand, China's consistent growth in GDP has been fuelling increasing demand for oil ${ }^{14}$ which an ill-developing domestic industry, facing at best since the late 1990s a plateau in production capacity, is unable to meet. This lack of growth in the oil sector is related in part to the forced decline (3\% to $5 \%$ yearly) of its major oil production area of Daqing (representing about $30 \%$ of its total production output), and in part to the limited and marginally over-compensating output delivered ${ }^{15}$ by emerging production from vast yet remote sources in China's west and some promising off-shore fields. It is also due to the insularity of its industry, which has been unable to protect its resources from international influence and which has kept it from forging significant foreign alliances, by which the industry could progress through the implementation of up-to-date technologies or production-sharing stimuli partnerships ${ }^{16}$.

19 The expanding oil deficit is leading China to become vulnerable to increasing and massive import requirements: the ratio of imports to total demand, negligible up to the late 1990s, was suddenly at about 30\% in 2003 (at a record 91 millions tons, rising 31\% over $2002{ }^{17}$ ), and is forecast to climb to $50 \%$ within a decade (and to $80 \%$ by $2030{ }^{18}$ ). In 
absolute terms, China's domestic net imports were about 15\% of US imports in 2001 and are likely to be about $60 \%$ in $2030{ }^{19}$. This incredible and apparently unnoticed deterioration in both the energy balance ratio and in the figures involved have obliged the local oil companies to search very vigorously for overseas sources of supply to secure strategic reserves and help level up this highly uncomfortable position of imbalance.

Concomitantly, this compulsory move towards some globalisation and "courting oil diplomacy" is observed as to be rather mono-directional as, on the other side, this call to embed China in the oil globalisation process has been attracting mute responses from the majority of the current giants, being supply countries or oil majors, with the relative exception of Russian and neighbouring republics keen to secure political and business presence into the cross-countries pipelines affairs.

Although both the top state authority ${ }^{20}$ and the three domestic oil companies (in addition to Sinochem ${ }^{21}$ ) have been leading comprehensive campaigns to invest in overseas oil fields and to sign some fixed long-term purchasing agreements, few significant deals have been working out successfully (CNPC/PetroChina intakes into Sudan and Ecuador (major stakes or operatorship in oil fields), Sinopec in Azerbaijan and Saudi Arabia (co-development deal) and CNOOC in Indonesia (assets buy-back)). For an official FDI (foreign direct investment) amount of about US $\$ 4$ billion spread across 20 countries ${ }^{22}$ and representing about $15 \%$ of the domestic players' total production capabilities ${ }^{23}$, those investments are dwarfed by the bulk of oil exchange concluded under straightforward trading contracts and implicating Middle-East producers in about $40 \%-50 \%$ of the total supply (Africa about 25\%-35\%). China, unlike Russia or promising countries such as Nigeria, Angola, Venezuela or the Caspian Sea republics, offers no exciting or valuable potential in oil exploration and production (E\&P) activities and accordingly is strategically more considered as a second-tier oil investment-driven partner. The refusal of the oil majors under the Caspian Sea Exploration Consortium in early 2003 to accept both Sinopec and CNOOC as replacement partners in one of the largest oil reserve areas in the world-the Kashagan field in Kazakhstan-using their pre-emptive rights is one of the most striking cases.

At the same time, the importance of China's trading and derivatives markets is clearly of great significance, these being a major factor of influence in international pricing fluctuations. This makes China an indispensable partner. A few domestic deals-in the Tarim Basin and offshore territories (Bohai and South China Seas)-and international agreements- i.e., recently Saudi Arabia and Yemen formed joint ventures now becoming operational, while others are under discussion. On the non-Chinese side, those deals aim at securing access to privileged areas of high growth oil derivatives markets in addition at building limited but profitable exposure to local E\&P. This illustrates a second globalisation process viewed as "medium-context", being the juxtaposition of primary global concerns from a China supply perspective and secondary concerns from the outside world more interested in China demand and consumer markets reservoirs.

Gas-a "high-context" process

24 The Chinese gas industry (and gas and oil pipelines) is subject to a "high-context" globalisation process. China wants to become a true global player fully recognised, inter-connected and integrated, both on natural gas and liquefied natural gas (LNG) feedstock, both on domestic and international fronts, and on gas and oil pipelines and 
gas fields projects. Historically, natural gas has been a minor fuel primarily consumed as a feedstock for fertiliser plants with little usage for electricity generation, which accounts for a small $2 \%$ of the total energy balance. But recent reassessment of three fundamental parameters have led China to embark on a massive three-pillar strategy of promotion, build-up and operation of gas and oil pipelines projects.

Firstly, China's substantial proven reserves have been reassessed at 150-200 trillion cubic feet (tcf) or $5 \%$ only of the estimated potential, giving substantial credit to a solid domestic-based industry. Second, key emerging climate and pollution environmental concerns are clearly influencing the current debate in favour of less polluting fossil fuels such as natural gas. Lastly, there is a determination to lower over-dependence on both coal and imported oil by ships-associated to the geo-political risk. This innovative policy contains a primary objective-to double the share of its gas usage by 2010 (production to rise to about $7.2 \mathrm{tcf}$ from $2 \mathrm{tcf}$ currently), aiming specifically at electricity generation and city distribution.

The first pillar consists of the exploitation-from exploration to distribution-of the most significant domestic deposits in Xinjiang (Tarim Basin, 30 tcf to $40 \mathrm{tcf}$ ) and Inner Mongolia (Ordos Basin, $16 \mathrm{tcf}$ to $21 \mathrm{tcf}$ ) through the setting-up of intensive E\&P works and the West-East Pipeline Project (valued at US $\$ 8.6$ billion) to carry, for about 30 years, $1.2 \mathrm{tcf}$ of gas per annum, the four thousand kilometres to Shanghai; and through the expansion of a countrywide pipeline network linking smaller deposits to other main consumer centres. Up to July 2004, PetroChina was the legitimate nominated leading force behind the first two operations (50\%), associated to participation from local rival Sinopec (5\%) and major international players such as Gasprom, ExxonMobil and Shell (each at $15 \%$ ).

The second pillar consists of discussion with Russia and the Central Asian republics of the exploitation of the gigantic oil and gas reserves belonging to its rich neighbours. Today four main projects are crucially pending. The first two are east Siberia projects: one managed by a trio formed by TNK (Tyumen Oil)-BP (together as Russia Petroleum), CNPC and South Korea's Kogas backing the exploitation of Kovykta fields (50 tcf) near Irkutsk. The project will link this part of Siberia to Manchuria and possibly South Korea (via an undersea route from Dalian onwards) through a 2,400-kilometre, 2.9 billion cubic feet per day capacity of pipeline with total costs estimated at US $\$ 14$ billion to US $\$ 17$ billion. The second is a parallel route project under a Memorandum of Understanding signed in July 2000 (and a general agreement in May 2003) for a YukosCNPC US $\$ 150$ billion partnership allowing about 750 million tons of oil to be shipped from Angarsk to Daqing through a US $\$ 2.5$ billion pipeline over the period between 2005 to 2030 (or about 30 millions tons a year equivalent to $5 \%$ to $10 \%$ of China's yearly average need). The third is the Kazakhstan project ${ }^{24}$, being the exploitation by a jointly owned company by CNPC and a Kazakh state oil and gas company, and a 3,100kilometre pipeline delivering 20 million tons a year of oil to western China. The fourth is the Sakhalin project to transport natural gas from the gigantic fields (operated by Japanese and majors oil and gas companies) situated on those tiny Russian islands on the northern tip of Japan to Harbin and Shenyang.

The third and final pillar consists of the exploitation of imported LNG through the build-up of terminal facilities and grids around the terminals to feed gas-fired power plants in addition to the securing of massive LNG reserves and supply contracts. Those LNG projects are estimated to account for $8 \%$ of China oil and gas imports by $2010{ }^{25}$. 
South and costal China have been prioritised with one terminal project in Shenzhen finally negotiated (over 3 millions tons per year and a cost of US\$600 million) and under construction (to be operational by 2006) while two others of similar size (most probably in the Xiamen and Shanghai areas) are planned for 2010. Here as well the logical China majority operator-CNOOC (both Corp. and Ltd.) is partnering with some key international contributors and some local authorities (BP 30\%, Guangdong province $31 \%$ for the Shenzhen project), while being granted three important international concessions in both E\&P fields and purchasing matters: a first US $\$ 20$ billion 25-year supply contract (70 million tons) from Indonesia's BP-led Tangguh field associated with a stake of $12.5 \%$ signed in 2002 (and subsequently raised early 2004 to 17\%); and two contracts (2002 and 2003) about US\$17 billion US\$20 billion each (25 years for 75 to 100 million tons) from Australia's Northwest Shelf (Woodside operated), and Gordon (ChevronTexaco operated) fields projects, both linked to participation into them (respectively $5 \%$ and $17 \%$ ).

In addition, beyond those three secured agreements, CNOOC also unveiled in early 2003 a plan to build a 2,100-kilometre pipeline linking those LNG terminals and the PetroChina West-East pipeline along a Shanghai-Fuzhou-Shenzhen-Guangxi coastal route. Sinopec is talking too about building a fourth LNG project in Shandong province ${ }^{26}$ while PetroChina is studying another Shanghai terminal ${ }^{27}$.

The globalisation process embedded in these three-pillar strategy and implementation practices, and the positive and negative implications, are outlined here.

The Chinese pipelines network

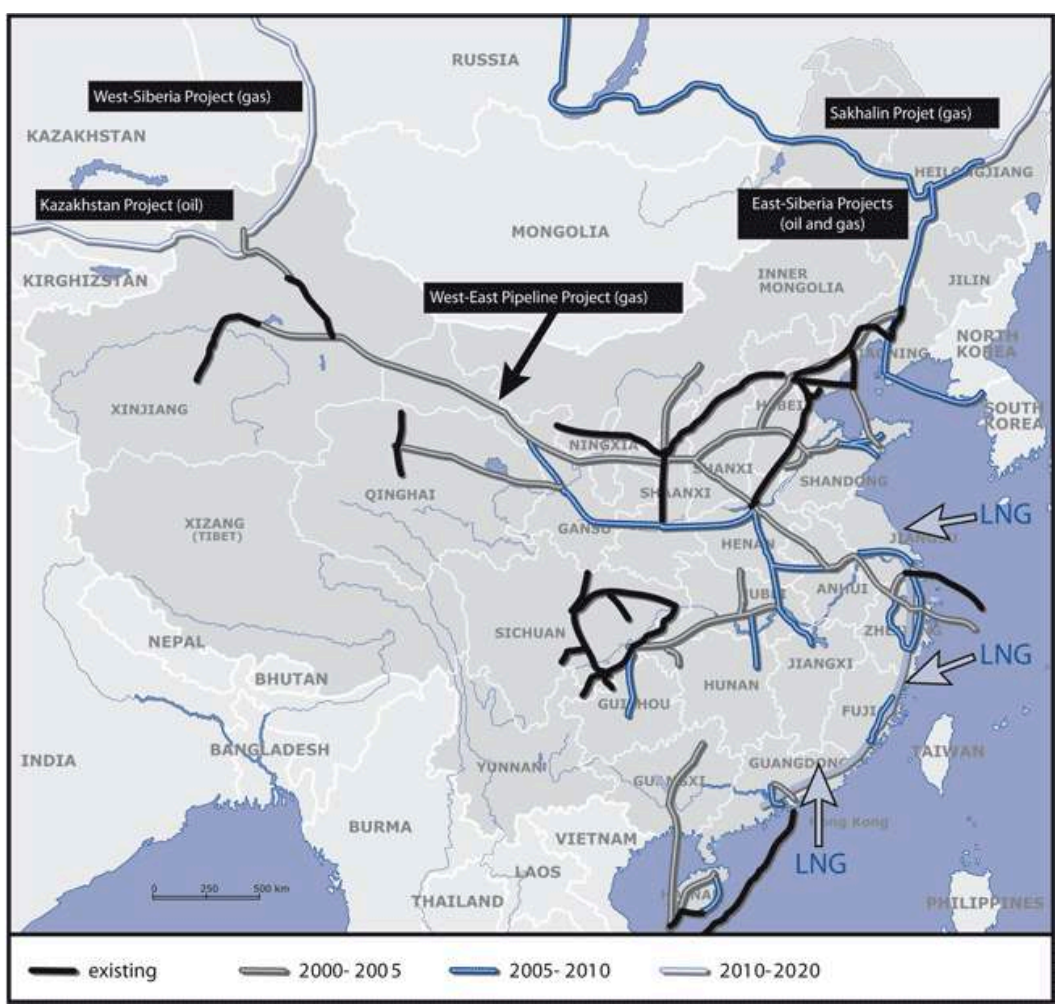

31 On the positive side, the mutual and complementary interests together with the strengths and weaknesses of both domestic and international partners are taken into account when building joint-venture schemes. The above projects are built on alliances 
between some of the best possible partners following intensive bidding and negotiation processes. It is for example well acknowledged that the hardware- and software-related technologies offered by the majors to PetroChina in the West-East Pipeline Project are crucial to the project's success; as the LNG supply contracts are to the LNG field developments. These deals are formulated as any serious business enterprise following orthodox economics free from domestic institutionalised rulings and practices.

At the same time, this new approach of applied global practice leads to an inevitable series of hurdles and integration into a "foreign" context-consideration of matters of economy of scale, financing, resolving mismatches between partners' strategic plans, and competitive alternatives, which have had a fundamental impact on project operations and to some extent even their existence. From initial stretched feasibility studies and delayed constructions work-only the west-east pipeline is well advanced and due for completion by end of 2005-, each of the projects has its globalisation-led obstacles. Yet even the west-east pipeline has faced ongoing unresolved pricing regulation and fixing debates, leading finally to the withdrawal of all foreign parties for disapproval of the latest economics offered ${ }^{28}$. As for the Russia and Central Asia oil and gas pipelines, both the agreeing and structuring of a joint pool of resources, as well as the setting-up of an organisation system from state down to every-day operations level, are pending. In addition, some geo-political and alternative business negotiations are working against the interests of those projects by highlighting other Central Asia pipelines routes under discussion (such as the US $\$ 3.6$ billion Azerbaijan Baku-TbilisiCeyhan or hypothetical Iranian line), and their partners. In particular, the indirect influence of the United States and Japan's competitive and aggressive courting of the Russian reservoirs, for identical strategic supply reasons, are making themselves felt. The Japanese counter-proposal for an east Siberia oil pipeline route (to Nakhodka port on the Sea of Japan despite being substantially longer-about 50\%-and twice as costly) supported by Russia state-owned monopoly firm Transneft, is antagonising the PRC-led projects with some success. The latest news suggests that Russia would opt for the Japanese route ${ }^{29}$. 
Henan mine in 2001. China is word leader in production and consumption of coal

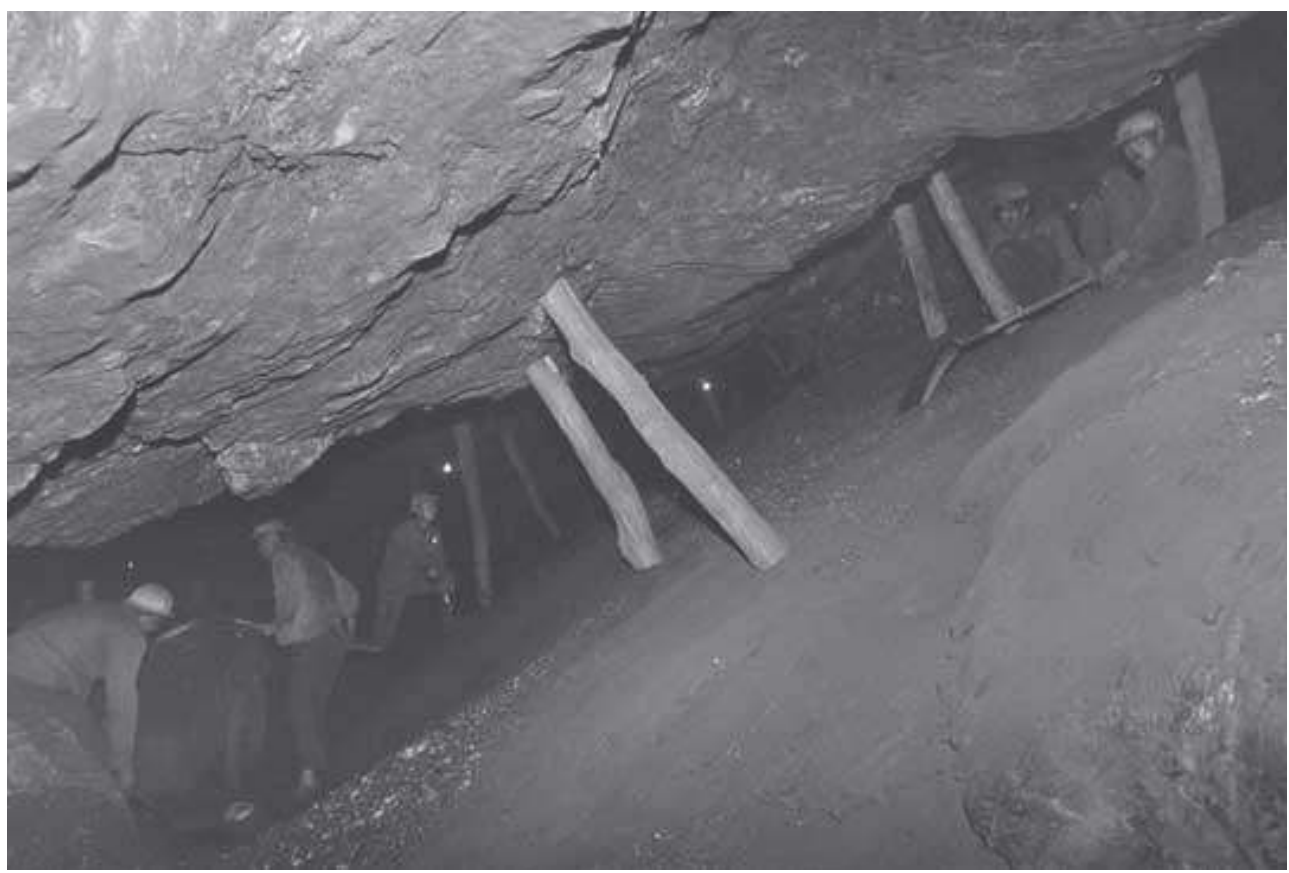

(C) Imaginechina

Electricity-a "mixed context" process

The final contributor to China's primary energy supply-electricity (nuclear and hydropower) and biomass-accounts for a small $3 \%$ of the whole, and should grow to about $4.5 \%$ by 2020 . Its globalisation process can be viewed as a synthetic mix of the three. A low-context process is typified by the setting-up of gigantic engineering works, nationalistic ego and a fixed assets booster such as the Three Gorges Dam Projectcontroversial from many points of view and built largely to typical local economics, safety and performance standards. 


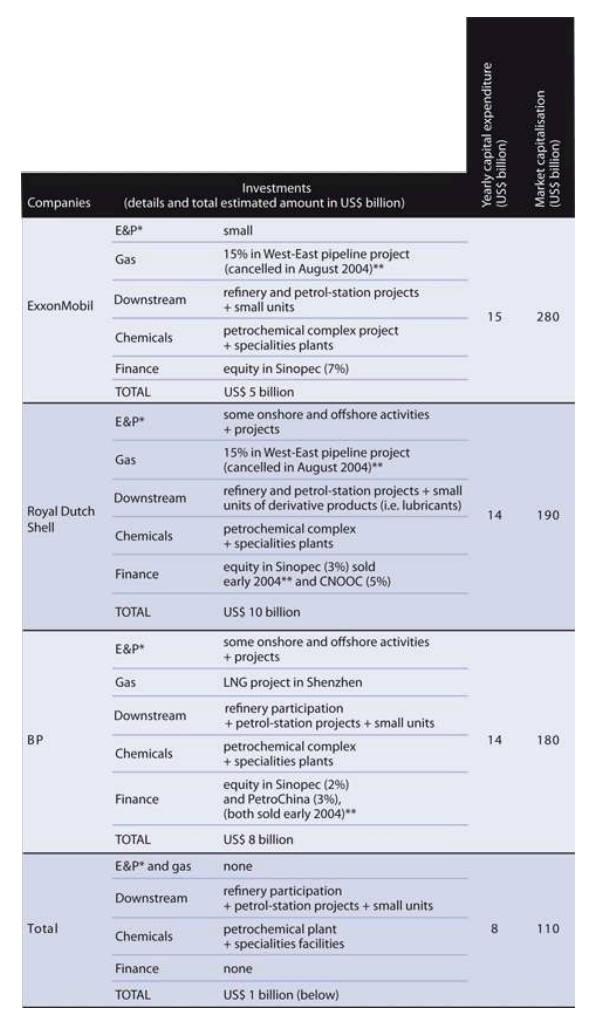

NB: Investments with relation to indicative end-2003 capital expenditures and market capitalisation. Including all before cancellation and/or sale. Excluding ChevronTexaco only marginally involved in E\&P offshore.

* E\&P = exploration and production. ${ }^{*}$ The corresponding amount are included in the total.

Sources: Websites of ExxonMobil (www.exxon.com), of Shell (www.shell.com), of BP (www.bp.com) and of Total (www.total.com) under "investor relations" heading (consultations of February 2003); personal files and aggregation.

Medium-context would be the painful restructuring process of the electricity production and distribution sectors initiated in the late 1990s, exemplified by the dismantling of the State Power Corporation-split into five generating assets companies strictly separated from transmission and distribution-; as well as by the plan to unify all regional grids into a national grid, as for the pricing system ${ }^{30}$ and the announced tentative policy of allowing in private capital ${ }^{31}$. A high-context picture emerges in the nuclear industry: few existing units have been built under all but solid international practices and its plan to expand its stock quite significantly is to follow a similar pattern of criteria. 
Daqing - once the main oil-producing region, now in decline

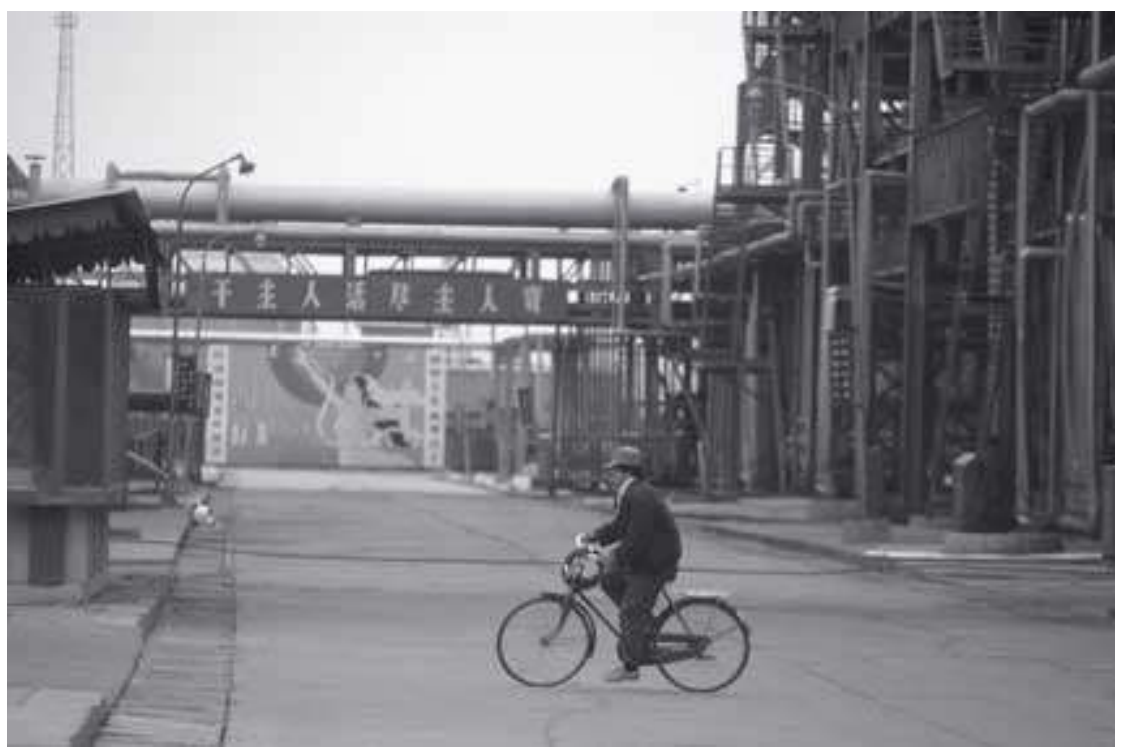

(C) Imaginechina

Overall, China is in conclusion a relatively global player, in evolution, moving within two decades from a completely self-sufficient, isolated and "a-global" position, to an integrated and interconnected power player with a definite character, although this status is largely pro-active upon necessity and still secluded within a relatively small percentage of its total energy supply requirements.

The Chinese oil \& gas industry facing the inner market and the outside world The 1998 shock therapy

Applying four key material concepts-industry structure, competition, technology and price-setting mechanisms to China's domestic oil and gas industry since the mid-1990s to the present-, we will identify where transformation towards a market economy-led globalisation stand with Chinese characteristics have occurred.

The industry picture changed fundamentally from 1995 on, with emerging restructuring efforts to merge and streamline a vast constellation of small to mediumsized oil and gas, and chemicals downstream operations countrywide, with the intention of forming regional coherent players. In particular to articulate some kind of a "Shanghai chemicals champion" centred around Shanghai Petrochemicals Corporation-being the flagship company model and the most visible H-share company floating on the Hong Kong stock market in that particular sector. The major change among all which followed happened in 1998, when the entire industry was fully restructured under a territory-based split between three giant companies: CNPC in the north and west (12 provinces) with the majority of oil and gas reserves, Sinopec Group in the south and east (19 provinces) with the bulk of the refining and chemicals assets, and $\mathrm{CNOOC}$ keeping its almost monopolistic off-shore perimeter intact ${ }^{32}$. Although clearly motivated by more than purely business motives, this comprehensive shake-up has produced a basic industry structure, to date the closest to "global" dimensions.

The major impact has been the emergence of a real competition phenomenon between and among CNPC and Sinopec affiliates, specifically significant on two distinct grounds: manufacturing and technology-led on one side through substantial process and technical upgrades initiatives; and market and client-base dynamic through products, 
quality improvements and uplifting marketing campaigns for market share and predominance in their respective assigned regions, on the other. After decades of uncompetitive and old-fashioned practices, the two companies are now aggressively restructuring their assets base, implementing production enhancements plans and using sales and marketing innovative tools, as much to set up programmes to improve their cost structures as to attract a brand new customer base. Western-style battles for market turf arose, to the point of requiring co-operation from archi-rival Taiwan China Petroleum Corporation to strengthen business against rivals.

The pricing mechanisms have been similarly progressing towards a semi-liberalised market value reflection from the same key 1998 reforms. In the oil sector, the settingup of a system coupling national references to internationally recognised quotes from the Singapore market currently prevails-although subject to local amendments (prices are adjustable within a one-month period and come under regime allowing discriminatory power and control thus legitimising some disparities). Concomitantly, the above-mentioned competitive field brought with it unprecedented price wars and spot periods of undervalued prices.

On the gas scene, the public policy-controlled value chain system has undergone several modifications to bring modern pricing methods integrating cost-structure type , flexibility pricing and take-or-pay mechanism considerations into play.

The influence of the majors and the WTO

Yet this reformulation of the industry falls short of three important characterisations for any sustained and comprehensive globalisation platform: good distribution networks and an efficient assets base closed to consumer markets; competition among national and international players; and a fully deregulated market structure.

The first handicap lies in the Chinese industry legacies and the inadequacy between supply and demand zones: the domestic production sites and facilities being disseminated and fractioned under a planned economy, often too concentrated into politically-selected remote locations, and furthermore often stuck in the old-regime north-east industrial hubs. This unfortunate combination of those two negative factors makes the whole industry ill-equipped to efficiently supply the booming consumption areas of development predominantly situated in south and central coastal regions. Additionally, a rustic distribution network system over-intensively mobilised to support such a critical material flow towards the consumption zones is an additional burden and creates deadlock. As a consequence this domestic consolidated industry picture reflects an outdated and far from optimised business model distant from a proper configuration attached to the majority of the Western world made of a few albeit huge facilities built along the major coastal economic centres. These supply chain deficiencies are well understood by the Chinese authorities and massive works are underway to slowly close the gaps. But it will take a minimum of two decades before there can be any realistic opportunity of the system approaching typical "Western" business models and thinking.

The second deficiency, linked to the first, is in the still marginal role and influences played by the international companies as shown in Table 2. Whatever specific industry sector visited, the international community holds a maximum of a small percentage of all activities-about $5 \%$ of existing E\&P oil \& gas activities, a negligible part in refineries, about $20 \%$ in small oil derivatives such as lubricants, and a negligible part in petrochemicals-and is emerging in other activities (oil, LNG, petrol stations, 
petrochemicals). Following decades of absence and a limited presence in the $1990 \mathrm{~s}$ through small investments, billions of US dollars are eventually spent by these majors on setting-up state-of-the-art facilities. But the amount of investment spent in China are still insignificant compared to their overall capital expenditure capabilities and their total enterprise value (considered as their market capitalisation). They are also under restrictive domestic rulings: no foreign majority is allowed in big projects, being all joint-ventures (JVs) ${ }^{33}$.

This experimental phase of concrete foreign business commitment and day-to-day interactions within the local set-ups appears well engaged as far as initial construction and early implementations works are concerned. But lacks any evidence of solid operational internationalisation practices.

The third deficiency consists of the prevailing numerous official restrictions and regulations-such as import duties and a vast array of local taxes-as well as unofficial prohibitive practices-as grey imports, false re-exports and dubious logistic transactions-which all combined are still obstructing the free flow of merchandise and limiting the scope of a fair and transparent competitive playing field. The WTO rulings related to this particular industry have started to bring some platforms for changes from 2002 onwards, with particular emphasis on two specific fronts: a progressive but eventually sharp reduction of all import duties, forcibly eliminating to a large extent the external official protectionism, and a similar drastic opening-up of the internal distribution system-from the progressive disappearance of quotas and licences for oil and derivatives imports (from 2004 onwards), to the full freedom granted to any retailing and wholesaling business (from 2005-6 onwards).

Although such normative impacts are occurring well in advance of any significant transformations in the everyday business arena, emerging strategic moves by both local and the international players, either to access, or to consolidate their position in, the distribution network industry, as well as an intensive clean-up of notorious corrupt import zones firmly indicate the will and determination to bring about change.

Domestic oil and gas companies, and international standardsPrivatisation as a trump card

The integration of the Chinese industry within the international energy world has been truly formalised through the listing vehicles of the three national companies, PetroChina, Sinopec Corp and CNOOC Ltd. Following the major 1998 structural changes-and in particular the principle of "separation of core business from the ancillary, good assets from the bad, and enterprise functions from the social" ${ }^{34}$, the three domestic entities quickly established a separate corpus with a similar goal: to create three champions, firmly under their national shareholding control and comprising their best assets and management, in order to be listed to raise fresh capital under optimised circumstances and with the ambition to aggressively pursue their restructuring (both in selective development and cost-cutting measures) as well as to model their business profile and success to the best international peers. Accordingly, PetroChina, Sinopec Corp and CNOOC Ltd were created late 1999 and early 2000, and listed mid-2000 to early 2001 under a public offering of about $10 \%$ to $27 \%$ of free-float.

Three years later, a comparison of some key performance parameters (see Table 3) reveals as much success as failure. First of all, the co-existence of three companies is not sustainable on a long-term basis, as neither is big enough nor sufficiently "integrated". Nor do they offer the critical size and locational combination of E\&P, 
downstream and chemical operations to optimise the value chains to be in a position to become a true global player. Only a combined entity would have a significant chance of standing as such-a 2003 aggregation of the three would for instance give a set-up in line with BP. This is understood by the Chinese authorities, though little has been done to achieve it ${ }^{35}$.

Second, the major success of the three firms consists in having massively re-engineered themselves through internal and external processes. Continuous assets swaps and offloading manoeuvres with their mother company and local municipalities, as well as some implementation of international practices, have enabled them to stand among the elitist list of the most competitive and efficient Chinese firms ${ }^{36}$ and to currently deliver financial performances in line with the majors and regional competitors (very much helped though by the 2003 buoyant international and domestic oil and gas scene).

Third, those successes cannot hide two major concerns: on one hand, their discounted enterprise valuations as per latest market capitalisation amounts still stand $20 \%$ to $40 \%$ lower than the majors; the explanation lies in the integration of an important risk and sustainable financial performance premium associated with their unproven record of continuous high-level profitability and a legitimate reserve about their ongoing tasks achievement towards a fully streamlined cost and revenue structure. On the other hand, the non-negligible impact of huge burdens and liabilities matters at the three head companies is taking its toll: matters such as a massive surplus of manpower ${ }^{37}$, multiple non-operational or under-utilised assets ${ }^{38}$, and various hidden losses of local SOEs. These problems are all only painfully slowly and partially being addressed.

Institutional comparison-encouraging signals

The 1998 rulings are the starting point for partial but significant institutional transformation towards global standards. From the macro-governance point of view, important structural changes have been achieved, leading today to a two-head authority centre. Tearing down decades of the entire energy industry governed by ministries, an initial set-up emerged as a tentative response, comprising the three players held strictly under a newly created central-core dedicated regulatory body: the State Administration of Petroleum and Chemical Industries (SAPC), placed under the authority of the State Economic and Trade Commission (SETC). Following the dismantling of both SETC and SDPC in 2003, and their replacement by the State Commission in Charge of Development and Reform (SDRC), an affiliated bureau-the Energy Research Centre-took over the responsibilities of the SAPC together with the Ministry of Commerce ${ }^{39}$.

The state-interventionism observed in key issues-such as strategic overseas E\&P campaigns, domestic policies on pricing changes, or appointment of top management leaders-while keeping at bay day-to-day operations, appear to dominate this current more market-oriented "light control" institutional scene. The SAPC could be compared to a kind of solid state supervisory board to supervise and guide major industry debates and competition between the three firms. 
Comparison of the three Chinese listed companies to one major and two regional referencesbenchmarked key parameters

\begin{tabular}{|c|c|c|c|c|c|}
\hline & $\begin{array}{l}\text { Turnover } \\
\text { (USs billion) }\end{array}$ & $\begin{array}{l}\text { Net result } \\
\text { (USs billion) }\end{array}$ & $\begin{array}{c}\text { Capital } \\
\text { expenditure } \\
\text { (USs bition) }\end{array}$ & $\begin{array}{l}\text { Market } \\
\text { capitalisation } \\
\text { (Uss billon) }\end{array}$ & $\begin{array}{l}\text { Production } \\
\text { (million barre oil } \\
\text { tquivalent a day? }\end{array}$ \\
\hline PetroChina & 36.5 & 8.4 & 10 & 90 & 25 \\
\hline Sinopec Corp. & 50 & 26 & 5.4 & 52 & 0.9 \\
\hline CNOOC Ltd. & 4.9 & 1.4 & 1.2 & 18 & 0.35 \\
\hline BP & 236 & 12.5 & 14 & 180 & 4 \\
\hline Petronas & 22 & 4.5 & $4-6$ & Fully state-owned & 1.3 \\
\hline Yukos & 17 & 5.5 & Notavailable & 28 & 1.7 \\
\hline
\end{tabular}

NB: Best estimates=end 2003 data.

Sources: Websites of PetroChina (www.petrochina.com.cn), Sinopec (www.sinopec.com), CNOOC (www.cnoocltd.com.cn), BP (www.bp.com), Petronas (www.petronas.com.my) and Yukos (www.yukos.com) under "investor relations" heading (consultations of February 2003); personal files and aggregation.

53 At the company level and in particular within their listed vehicles, which are most visible to and under international scrutiny, some apparent changes formalising strict internal corporate governance principles and moves towards decision-making transparency and following market economy fundamentals are taking place.

The typical Western-applied managerial organisational "matrix system" (a combination of geographical and operational hierarchy, both at local and headquarters levels) has also been put in place gradually and seems to be having some success, although curbed by the autonomous power linked to a large number of geographical-independent sites of oil and chemical complexes which are for historical reasons run as semi-autonomous kingdoms. Often enormous, representing a major economic force within their territory and deeply embedded within the local institutional context, they tend to inhibit this organisational optimisation.

A fight between old and new

The business and societal concepts of consumer-driven production facilities and of responsible care were completely out of touch with any PRC market realities up to the late 1990s. China's oil and gas industry was no exception. The last five years have shown signs that such "alien" concepts are being recognised, within three distinct phenomena.

56 Firstly, a "Westernised conscience" is slowly taking ground within a class of welleducated (often abroad) low to medium managers, in contact and at ease with such "revolutionary" ideas. These managers are gradually introducing foreign practices and developing innovations that aim to optimise production assets and delivering products matching customer expectations. Although blocked by a wall of bureaucratic middlemanagement, some of those changes are relayed by the top cadres, for the majority highly competent, well-suited to the job and enthusiastic about their implementation.

57 Secondly, this action and reaction link between those two managerial layers are strengthened by a new corporate culture promoting a meritocracy, unfixing bit by bit some strict hierarchy or salary habits unrelated to individual performance.

58 Thirdly, companies' responses to safety and societal matters have been evolving towards substantiated responsibilities becoming evident and a need for these to be accepted and taken up by those companies. The Chongqing gas blast in December 2003, involving CNPC, which killed 243, obliged the company to take prompt action to 
guarantee compensation and a thorough investigation, and to sack local figures as well as a top figure (intense pressure eventually forced the resignation of his president $\mathrm{Ma}$ Fucai). This incident stands as a good example of current expectations of all three companies in terms of their obligations within a globalised industry, somewhere on a long and strenuous journey towards comprehensive global capabilities.

More fundamentally, professional business research on this spectrum of globalisation into Chinese corporations authenticates and validates five qualifying criteria ${ }^{40}$ : an important domestic market, high ambition to become a leader, a global corporate governance status, operational excellence and distinctive capabilities. Petrochina, Sinopec and $\mathrm{CNOOC}$ meet the first two criteria, while the third is questionable and the last two are not yet met.

A globalisation process then seems in train: solidly initiated through sound and valuable structures, progressive and holding to modernisation principles validating key market economy parameters, but still significantly far from any fully rational business model. This rationality is seen as crucial to support the pursuit of its transformation, which needs to become self-perpetuating, self-regulating and self-managed, and not so much dictated by internal pressures and external circumstances.

\section{NOTES}

1. These three companies are officially state-owned enterprises, while their respective listed vehicles-PetroChina, Sinopec Corp and CNOOC Ltd-are their partially but majority-owned subsidiaries. The former companies are restructured entities from the 1998 reshuffle, while the later ones are newly emerged and set-up from the stock listing process of 2000 and 2001.

2. These five are commonly denominated as majors on the business, consultancy and banking scene and literature, and are defined as publicly-owned firms with a minimum production of two millions of barrels of oil per day.

3. A standard banking and financing practice consisting of initiating a publicownership process from a private or state-owned enterprise through issuance of stocks. 4. Ulrich Steger (ed.), Discovering the new pattern of globalization, Ladenburg: Gottlieb Daimler-und-Karl Benz-Stiftung, 1998.

5. John Child, "Theorizing about organization cross-nationally", Advances in International Comparative Management, Vol. 13, 2000, pp. 27-75. Child posits a triangular inter-connected system that has an impact on a (cross-)national organisation or body; this system is made of three spheres: material, institutional and ideational, each consisting of different inputs, contingencies, capabilities, constraints and references in relation with that organisation or body.

6. Ibid.

7. Mehmet Ogutcu, "Energy prospects and investments in China", OECD Conference, Xiamen, 2000 and International Energy Agency (IEA), China Worldwide Quest for Energy Security, IEA Press, 1999. 
8. Four different sources are defined: solid (primarily coal), liquid (primarily oil), gaseous (primarily natural gas), and others (primarily hydro-electric, nuclear and biomass).

9. Data from George Murdock, China Energy Crisis, Dresser-Rand Business Development Paper presentation in Hong Kong, 2000, and IEA, China Worldwide Quest for Energy Security, IEA Press, 1999.

10. K. Song, "China Huge Power Appetite", Far Eastern Economic Review, December 18th 2003.

11. Financial Times, December 16th 2003.

12. A quota system aimed at restricting export volume during tightening supply periods was to be in place by July 2004. South China Morning Post, January 24th 2004. 13. South China Morning Post, December 13th 2003 and Renmin Ribao, December 22nd 2003.

14. For every percentage-point growth in its economy, China is projected to register an equal percentage growth in oil consumption. See G. Dietl, "Middle Kingdom and the Middle-East: the energy connections", China Brief, February 2003.

15. Experts speculate at best about an incremental growth of 2\%; source: Arthur Kroeber, "China's oil quest", China Quarterly Review, March 2003.

16. With the notable exception of offshore business open to some co-operation since the early 1980 s.

17. Asian Wall Street Journal, January 20th 2004.

18. Financial Times reporting IEA data, January 21st 2004.

19. Pierre Noel, "Energie et relations internationales, Les Etats-Unis et la Chine", colloque Ifri, March 2003.

20. President $\mathrm{Hu}$ Jintao made his latest significant trip in January 2004-a ten-day tour of Europe and Africa, including three important stop-overs in Gabon, Algeria and Egypt to settle hydrocarbons deals. See: South China Morning Post, January 20th and 28th 2003, Wall Street Journal, February 6th 2004.

21. Sinochem (China International Chemicals Import \& Export Corporation) being up to recently the de facto state company officially in charge of oil and chemicals import and export business.

22. Extracts and estimations out of UNCTAD, "China: an emerging FDI outward investor", E-Brief, December 2003.

23. Report on Energy in China, Citigroup Research, May 2004.

24. See D. Murphy, “Asia's Pipelines Politics”, Far Eastern Economic Review, July 24th 2003; Arthur Kroeber, op. cit.; The Moscow Times, Financial Times, Asian Wall Street Journal, various editions; and IAI, op. cit.

25. Arthur Kroeber, op. cit.

26. Asian Wall Street Journal, April 17th 2004.

27. Yahoo Finance, financial news, internet, April 28th 2004.

28. South China Morning Post, August 3rd 2004.

29. Financial Times, May 12th 2004.

30. The Energy Information Administration (EIA), www.eia.doe.gov/emeu/cabs/ china.html, January 2004.

31. The Standard, February 3rd 2004.

32. 2002 data indicate that CNPC holds $67 \%$ of total oil and gas production while Sinopec holds $52 \%$ of all oil processing facilities and $66 \%$ of petrochemicals units 
(Ethylene). Sources: websites of CNPC (www.cnpc.com.cn ) and Sinopec Corp. (www.sinopec.com) under company profile heading; and personal files.

33. Wholly-owned foreign enterprises are only allowed for small projects and forbidden in some sectors.

34. Website of Sinopec Corp. (www.sinopec.com) under Investor Profile heading, January 2004.

35. Moves in 2004 such as PetroChina trying to enter offshore business and CNOOC refinery business indicate a preliminary shake-up in the direction of consolidation. See Financial Times, July 12th 2004.

36. Sinopec Corp was listed as the most competitive domestic-listed company in 2003 by the Chinese Academy of Social Sciences. CNOOC Ltd figures among the best ever credit-risk ranked company in China by Standard \& Poor's-BBB+ rating as good as China's long-term sovereign ranking. Sources: The Standard, September 23rd 2003, and Standard \& Poor's, "China corporates upgraded following Sovereign action", February 19 th 2004.

37. Figures of over one million people under CNPC protection and its payroll are often released. PetroChina has a workforce of 420,000 and CNOOC about 20,000. By comparison, $\mathrm{BP}$ has 115,000 people and only a few thousand people to realise the same turnover as CNOOC. Source: $\mathrm{CNOOC}$ websites (www.cnooc.com.cn) and BP (www.bp.com); PetroChina annual results 2003, South China Morning Post, March 25th 2003; personal files.

38. SOEs like CNPC and Sinopec Group carry non-operational assets such as schools and hospitals, and also hold a significant interest in old and inefficient factories or oil wells. 39. CEFC, "Review of Chinese Energy Strategy", internal document, 2003.

40. Jonathan Woetzel (McKinsey), "Globalisation among Chinese corporations", seminar "The Chinese World: moving forward", French Chamber of Commerce and Industry, Hong Kong, November 2003. 